Kitap Eleştirisi 



\title{
Şeffaflık Toplumu: Şeffaf Toplumun Eleştirisi Üzerine Bir Okuma
}

\author{
Derya Gül Ünlü
}

doktor, istanbul üniversitesi iletişim fakültesi

halkla ilişkiler ve tanıtım bölümü derya.gul@istanbul.edu.tr

\author{
Han, B. (2017). Şeffaflık Toplumu \\ (H. Barışcan, Çev.), İstanbul: Metis Yayınları
}

\section{Abstract}

\section{Transparency Society}

Transparency Society, written by Byung-Chul Han, responds critically to questions such as "how has the society evolved and became transparent due to communication technologies", and then "how have these transparent social structures changed?" The book focuses on how communication makes a society transparent and how this transparent communication transforms society via digital communication technologies. In his study, Han deals with the transformation of social technologies with the development of communication technologies through transparent communication, control society, and digital panopticon. In this context, it is possible to say that the basic of Han's work is how the understanding of freedom in the transparent social structure is restructured in a controlled society. In the context of critical approach, Han's transparency has been included in the review work on the thoughts on society.

keywords: transparency society, transparent communication, digital panopticon 


\section{Résumé}

\section{La société de transparence}

La société de transparence, écrite par Byung-Chul Han, répond à des questions telles que "comment la société a évolué et est devenue transparente grâce aux technologies de la communication ?" et "comment ces structures sociales transparentes ont-elles changé ?". Ce livre sur les technologies de communication numérique met l'accent sur la manière dont la communication rend la société transparente et comment cette communication transparente transforme la société. Dans son étude, Han traite la transformation des technologies sociales et le développement des technologies de communication à travers la communication transparente, la société de contrôle et le panoptique numérique. Dans ce contexte il est possible de dire que la compréhension de la liberté dans la structure sociale transparente est restructurée dans une société contrôlée.

mots-clés: société de transparence, communication transparente, panopticon numérique

\section{Öz}

Byung-Chul Han tarafından kaleme alınan Şeffafık Toplumuadlı eser, iletişim teknolojilerinin gelişip yaygınlaşmasıyla gündeme taşınan "iletişim teknolojileri dolayısıyla toplum nasıl evrilip, şeffaflaşmıştır?" ve beraberinde "şeffaflaşan bu toplumsal yapılar nasıl bir değişime uğramıştır?" sorularını eleştirel bir bakış açısıyla yanıtlamaktadır. Söz konusu kitap, dijital iletişim teknolojileriyle birlikte, iletişimin toplumu nasıl şeffaf bir yapıya büründürdügünü ve bu şeffaflaşan iletişimin toplumu nasıl dönüştürdügüü üzerinde durmaktadır. Han, çalışmasında iletişim teknolojilerinin gelişimiyle toplumsal yapının geçirdiği dönüşümü şeffaf iletişim, kontrol toplumu, dijital panoptikon gibi kavramsallaştırmalar üzerinden ele almaktadır. Bu bağlamda, çalışmanın temel dayanağının, şeffaflaşan toplumsal yapıdaki özgürlük anlayışının bir kontrol toplumu içerisinde nasıl yeniden yapılandığının açıklanması olduğunu söylemek mümkündür. Söz konusu eleştirel yaklaşım bağlamında, Han'ın şeffaflık toplumu üzerine ortaya koyduğu düşüncelere, gerçekleştirilen inceleme çalışması içerisinde yer verilmiştir.

anahtar kelimeler: şeffaflık toplumu, şeffaf iletişim, dijital panoptikon 


\section{Giriş}

Berlin Sanat Üniversitesi'nde ders veren ve felsefe, etik, fenomenoloji, kültür kuramı, estetik ve medya gibi konularla ilgilenen Han, şeffaflık toplumu isimli çalışmasında iletişim teknolojilerinin gelişimiyle birlikte bireysel ve toplumsal düzeyde nasıl bir dönüşüm yaşandığı üzerinde durmaktadır. Çalışma, teknolojik gelişmelerle birlikte toplumsal ilişkilerin şeffaflaştığı ve toplumsal yapının da aynılaştığı görüşü üzerine temellenmektedir. Bu bağlamda yazar, toplumun şeffaflaşmasının ne anlama geldiğini ve şeffaflaşmaya dair algılanan olumluluğun aslında özgürlükleri nasıl dönüştürdüğünden bahsetmektedir.

Byung-Chul Han, şeffaflık toplumunu dokuz farklı toplumsal özellik üzerinden tanımlamakta ve açıklamaktadır. Bunlar olumluluk toplumu, teşhircilik toplumu, apaçıklık toplumu, porno toplumu, ivme toplumu, teklifsizlik toplumu, enformasyon toplumu, ifşa toplumu ve kontrol toplumudur. Han, bahsedilen bu kavramsallaştırmalar aracılığıyla şeffaflaşan toplumsal yapının nasıl bir özellikler bütününe sahip olduğuna değinmektedir. Han'a (2017, s.59) göre şeffaf toplum, ışık olmaksızın içini gösteren toplumdur. Çünkü bu şeffaflığı sağlayan bir ışık kaynağı değil, toplumsal yapıdaki her şeyin içinden geçen ve her şeyi görünür kılan bir varoluştur. Bu varoluş toplumsal yapının tüm parçaları için homojenleştirici ve düzleştirici bir etki göstermektedir. Toplumsal yapının bu değişen varoluşu, hem kişilerarası hem de gruplar arası ilişkilerde yaşanan farklılaşmayı da beraberinde getirmektedir. Bu kapsamda, aşağıda, bileşenleri üzerinden açıklanan şeffaflaşan bu toplumun yeni biçiminin temel özelliklerine yer verilmektedir.

\section{İnceleme}

Byung-Chul Han, şeffaflık toplumu isimli çalışmasına dijital iletişimin dönüştürücü gücünün, bireylerin bu ağın dışında kalmasını imkânsız hale getirdiğinden ve tüm toplumsal birimleri şeffaflaştırdığından bahsederek başlamaktadır. Bu imkânsızlık nedeniyle, toplumsal yapı içerisinde farklı bir görüşü ifade etmek de her zamankinden daha zor hale gelmektedir. Bu bağlamda Han şeffaf iletişimin temel özelliğini aşağıdaki gibi ifade etmektedir (Han, 2017, s.12):

\footnotetext{
"Şeffaf iletişimin her şeyi düzgünleştirici, hizaya getirici bir etkisi vardır. Eşzamanlıığa ve bir örnekliğe yol açar. Ötekiliği ortadan kaldırır. Uyum sağlama zorlaması şeffaflıktan kaynaklanır. Böylelikle şeffaflık egemen sistemi sabitleştirir. Şeffafık insanı camlaştırır. Şiddeti de buradadır. Sınırsız özgürlük ve iletişim topyekün kontrol ve gözetime dönüşüyor."
}

Şeffaflaşan bu yeni toplumsal yapının farklı özellikleri bulunmaktadır. Bunlardan ilki, toplumsal yapının bir olumluluk toplumuna dönüşmüş olmasıdır. Han olumluluk toplumunu (2017, s.15); olumsuzluğun tasfiye edilerek, yerine olumluluğun konulması olarak ifade etmektedir. Şeffaflık toplumu kendini öncelikle bir olumluluk toplumu olarak gösterir. Dolayısıyla bir toplumun 
şeffaflaşması, tüm olumsuzluklardan arınması anlamına gelmektedir. Böylelikle, bireyin gerçekleştirdiği tüm eylemler operasyonel bir hale getirilmekte, hesaplanabilmekte ve kontrol edilebilmektedir. Ancak bu durum sistematik bir zorlamanın da habercisidir. Çünkü toplumsal sistemin tüm süreçlerini hesaplayabilmek, bireyleri şeffaflaşmaya zorlamak anlamına gelmektedir. Bu zorlama da sisteme katılmayan her bireyin (yani dijital iletişim süreçleri içerisinde yer almayan, sosyal ağlara katılmayan her bireyin) yabancı ilan edilmesine neden olmaktadır. Şeffaflaşan bu yeni toplumsal yapı içerisinde yabancı ilan edilen birey, dışarıda bırakılarak, sisteme istikrar ve hız kazandırılmaktadır. Han'a göre, bu sistematik zorlama, şeffaflık toplumunu hizaya getirilmiş bir topluma dönüştürmektedir. Dolayısıyla şeffaf toplumun bireyi, bir olumlulaştırma çabası içerisinde, toplumsal yapının işlevsel bir öğesi haline gelmeye mecbur bırakması, dönüşen yeni toplumsal yapının pasif şiddetini de düşünmeyi gerekli kılmaktadır.

Diğer yandan bu şeffafık, gizliliğin sonu olduğundan siyasal sorgulamanın da sonunu beraberinde getirmekte, adeta mevcut sistemin iktidarını güçlendirmek için görev yapmaktadır. Çalışmasında yazar, mevcut sistemin iktidarının nasıl güçlendirildiğini ve bu amaçla ötekinin nasıl dışarıda bırakıldığını aşağıdaki gibi aktarmaktadır (2017, s. 23):

"Şeffafık zorlaması mevcut sisteme iktidar kazandırmak açısından oldukça etkilidir. Şeffaflık kendi başına olumludur. Mevcut siyasi-ekonomik sistemi kökten sorgulayabilecek olumsuzluğu içermez. Sistemin dışındakilere kördür. Sadece mevcut olanı onaylar ve optimize eder. Bu nedenle de şeffaflık toplumu siyasal-sonrası ile birlikte varolur. Sadece siyasetten arındırılmış alan tümüyle şeffaftır."

Olumluluk toplumu, aslında her bireyin fikren de aynılaşmasını içermekte ve kamusal tartışma ortamını da intiyaçsızlaştırmaktadır. Böylelikle her birey bir diğerine bağlanmakta ve (b)ağlı bireylerden oluşan toplum transparan hale gelmektedir. Aynı zamanda dönüşen toplum, iletişimin bu sürekli yapısına ekonomik bir değer de atfetmektedir. Yazar bu süreci, sosyal ağların yapısal özellikleri üzerinden aşağıdaki örnekle açıklar (2017, s.23):

"Olumluluk toplumunun genel yargısı Like/Beğendim'dir. Facebook'un Dislike/Beğenmedim seçeneği sunmamaktaki kararııı̆ı anlamlıdır. Olumluluk toplumu, iletişimi sekteye uğratacağı için olumsuzluğun her türünden kaçınır. iletişimin değerinin tek ölçütü de enformasyon değiş-tokuşunun hacmi ve hızıdır. Hacmin büyümesi iletişimin ekonomik değerini de arttırır. Olumsuz yargılar iletişimi olumsuz yönde etkiler. Iletişim 'Beğendim'e kıyasla daha çabuk kurulacaktır. Reddetmenin taşıdığı olumsuzluk her şeyden önce ekonomik olarak değerlendirilemez."

Bununla birlikte Han, şeffaflıkla gerçekliğin özdeş olmadığını da vurgulamaktadır. Ona göre, daha fazla enformasyona ulaşmak beraberinde gerçeği getirmemektedir. Çünkü bu aşırı enformasyon anlam eksikliği taşımaktadır. 
Dolayısıyla enformasyonun fazlalığı, gerçekliğin de fazlalığı anlamına gelmemekte, aksine gerçeğe ilişkin belirsizliği daha da arttırmaktadır.

Han'a göre, olumluluk toplumu içerisinde şeyler, var olabilmek için sergilenmiş olmak ${ }^{1}$ durumundadırlar. Bu toplumda meta haline gelmiş olan her şey sergi değeri kazanmak için kült değerini yitirmiştir. Ancak sergilenebilen ve ilgi üretebilen nesneler değer kazanmaktadırlar. Bu perspektiften hareketle Han, olumluluk toplumunun bir özelliğinin de teşhircilik toplumu olmak olduğunu ifade etmekte ve teşhircilik toplumu kavramsallaştırmasını aşağıdaki gibi aktarmaktadır (2017, s. 27-28):

\begin{abstract}
"Teşhircilik toplumunda her özne kendi reklam nesnesidir. Her şey sergi değeriyle ölçülür. Teşhircilik toplumu pornografik bir toplumdur. Her şey dişa çevrilmiş, ifşa edilmiş, çıplaklaştırılmış, soyulmuş, ortaya serilmiş durumdadır. Teşhir etmenin aşırılığı her şeyi 'tüm sınırlardan arınmış olarak derhal tüketilmeye açık' bir meta haline getirir. (...) Sadece sergilenmeye yarayan sahnelenmedir değer yaratan, şeylerin her türlü kendine özgülüğü feda edilmiştir."
\end{abstract}

Han, teşhircilik toplumunda, sergi değerinin önem kazanması dolayısıyla, insan bedeni de dahil olmak üzere, her şeyin sergilendiğinden ve bunun müstehcen bir varoluşa yol açtığından bahsetmektedir. Bununla birlikte sergilenen nesnenin değeri de onun güzel görünüşüyle ölçülmektedir. Dolayısıyla sergilenenlerin ne kadar güzel göründüğü, onun sergi değerinin de ne kadar yüksek olduğunun karşılığıdır. Han'a göre (2017, s. 29) sergi değeri içsel değerleri değil, gerekirse zora başvurarak uyulmaya çalışılan dışsal ölçüleri sunmaktadır. Sergileme zorlaması görünür olanın ve dışsalın mutlaklaştııımasına yol açar. Görünmez olan, hiçbir sergi değeri, hiçbir ilgi yaratmadığı için, yoktur. Varolma gerekliliğine dönüşen sergi değeri, bir zorlamayı da beraberinde getirmektedir. Çünkü Han'a göre sergilemek, görünür olanın sömürülmesi anlamına gelmekte ve teşhircilik toplumunda her şey görünür olmak durumunda olduğundan, görünür olmayan her şey de şüpheli bulunmaktadır. Sergi değeriyle donatılmış resimler karmaşıklık içermemekte ve üzerinde tekrar düşünülmeyi gerektirmemektedir. Bu nedenle de, şeffaflaşan toplum anlamı giderek kaybetmektedir. Diğer yandan kaybolan tek şey anlam değildir, mesafe de bir dönüşüm içerisindedir. Şeffaflık toplumu kendi yapısı gereği her türlü mesafeyi dönüştürmüştür. Ancak bu dönüşüm yakınlığa doğru değil, bir mesafesizliğe doğru olmuştur. Mesafesizlik, mekanı yok etmiştir. Han'ın ifadesiyle (2017: s.30) şeffaflık her şeyi ne yakın ne de uzak olan birörnek mesafesizliğe doğru uzaklaştırmıştır.

Han'a göre şeffaf toplum, bir simetri toplumudur. Bu simetri, bütün asimetrik ilişkileri ortadan kaldırmaktadır. Yazar bunlardan birinin de güç

1 Han, burada Walter Benjamin'in nesnelerin kült değerleriyle ilgili olan düşüncelerine değinmektedir. Benjamin'e göre, nesnelerde önemli olan görülmelerinden ziyade mevcudiyetleridir. Han burada Benjamin'in 'kült değeri' ve olumluluk toplumunun 'sergi değeri' arasında bir karşılaştırma yapmaktadır. Ancak Han, Benjamin'in aksine, olumluluk toplumunda artık nesnelerin ancak sergilenip, görülebildiklerinde değer kazandıklarını belirtmektedir. 
olduğundan bahsetmektedir2. Güç, bireylerin diğerlerinin davranışlarına yön verme isteğini de beraberinde getirmektedir. Han'ın tanımlamasına göre bu güç (2017, s.34) stratejik bir oyundur ve kamuya açık bir alanda oynanmaktadır. Bu durum bir apaçıkığı da beraberinde getirir. Çünkü şeffaf bir toplumda, saklı olan, olumsuzluğun bir ifadesidir. Bu nedenle de saklı olanı, keşfetme, çözme ifşa etmeye dönüşmektedir. Han şeffaf toplumun bu apaçık olma halinin pornografik bir durum olduğunu düşünmektedir. Yani sergi değeriyle patlayacak kadar dolmuş olmak pornografik bir durumdur. Bu bağlamda Han şeffaf toplumun pornografik olma halini şu cümlelerle açıklamaktadır (2017, s.41):" Pornografi tam da topyekun teşhir ve soyma uğruna sırrın ortadan kaybolduğu noktada başlar. Müdahaleci, nüfuz edici bir olumlulukla kendini gösterir." Bu bakış açısından yola çıkan Han, günümüzde medyanın da mesafeden yoksun olduğu, kültürel niteliklerinden arındığı ve her şeyin apaçık ortada bulunmasından dolayı pornografikleştiğinin altını çizmektedir.

Bunun yanı sıra, Han çalışmasında, şeffaflaşmanın kültürel farklııkları da ortadan kaldırdığına değinmektedir. Han'a göre şeffaflaşmak, toplumun tüm yapısal öğelerine bir ivme kazandırmış, tüm toplumsal süreçleri hızlandırmıştır. Örneğin, ayin ve törenler hızlandıııması mümkün olmayan, anlatısal süreçlerdir. Bir kurban ya da hac törenini hızlandırmak, saygısızlıktır. Ayin ve törenlerin kendilerine has zamanları, ritimleri, ölçüleri bulunmaktadır. Ancak şeffaflık toplumu ayinlerin, törenlerin ya da mekanların hepsini ortadan kaldııır, çünkü bunlar işlemsel bir hale getirilememektedir. Bu nedenle de Han (2017, s. 50), şeffaflık zorlamasının şeylerin ve zamanın rahiyasını yok ettiğini ileri sürmektedir. Ona göre, şeffaflı̆ıın rahiyası bulunmamaktadır.

Han'a göre (2017, s. 53), günümüz dünyası mahremiyetlerin sergilendiği, satıldığı ve tüketildiği bir pazardır. Bu pazar, pornografik bir sergiyi yani teşhiri içermekte, bu da bir teklifsizlik kültürünü beraberinde getirmektedir. Han, tanımladığı bu teklifsizlik kültürünü aşağıdaki gibi açıklamaktadır (2017, s. 54):

\begin{abstract}
"Teklifsizlik kültürü, mahrem duygu ve yaşantıların nesnesi olmayan nesnelkamusal dünyanın çöküşüyle ortaya çıkar. Teklifsizlik ideolojisine göre toplumsal ilișkiler, bireylerin iç, psișik intiyaçlarına ne denli yaklașırlarsa o denli gerçek, hakiki, güvenilir ve otantik hale gelir. Teklifsizlik şeffaflığın psikolojik formülüdür. Mahrem duygu ve hissiyatlar ortaya konduğunda, ruh çıplaklaştırıldığında ruhun şeffaflığına eriştiği düşünülür. "
\end{abstract}

Han, yukarıda yer verilen teklifsizlik kültürü ile sosyal medya ve kişiselleştirilmiş arama motorları arasında yakın bir ilişki kurmaktadır. Ona göre (2017, s. 54), sosyal medya ve kişiselleştirilmiş arama motorları, dışarısının ortadan kaldırıldı̆ı mutlak bir yakın alan oluşturmaktadır. Burada birey yalnızca

2 Han, bu bölümde insanların neden güç uygulama eğiliminde olduklarını libido ekonomisi ve haz ekonomisi arasında bir ilişki kurarak açıklamakta ve Foucault'un haz ekonomisine atıfta bulunmaktadır. Bu bağlamda, insanların birbirleriyle olan ilişkilerindeki özgürlükleri ne derece fazlaysa ötekilerin davranışlarının belirlenmesine duyulan istek de o kadar büyük olmaktadır. 
kendisi ve kendisi gibi olan diğer bireylerle karşılaşmaktadır ${ }^{3}$. Dolayısıyla değişimi mümkün kılacak herhangi bir 'olumsuzluğun' varlığından da haberdar değildir. Bu dijital mahalle, dünyanın bireylerin hoşuna gideceği bölümlerini sunmaktadır. Böylelikle de kamusal alanı, kamusal ve hatta eleştirel bilinci ortadan kaldırarak dünyayı özelleştirmektedir. Internet mahrem bir alana, bir rahatılık ortamına dönüşmektedir. Bu her türlü uzaklıktan arınmış yakınlık da şeffaflığın dışa vurum biçimlerinden biridir. Böylelikle, bu teklifsizlik durumu her şeyi psikolojileştirmekte ve kişiselleştirmektedir. Han'a göre, kamusal alanın kaybolması, içine mahrem ve özel meselelerin döküldüğü bir boşluk yaratmaktadır. Han'ın deyişiyle, kamusalın yerini kişinin yayımlanması almaktadır. Böylece kamusal alan bir teşhir mekanı haline gelmekte ve ortak eylem alanı olmaktan giderek uzaklaşmaktadır.

Bu durum, toplumsal yapıda da birtakım dönüşümlere yol açmaktadır. Han, insanların aralarındaki mesafeyi koruyabildikleri derecede toplumsallaştıklarından bahsetmektedir. Ancak dönüşen toplumsal yapıda, bireylerarasındaki mesafenin ortadan kalkması toplumu teklifsizleştirmektedir. Han'a (2017, s. 55) göre, bu teklifsizlik toplumu, psikolojikleştirici ve ayinden arınmış bir toplumdur. İtirafın, soyunmanın ve pornografik mesafesizliğin toplumudur. Çünkü insanın kendisinden uzaklaşmasını, kendini kaybetmesini sağlayan ayinsel, törensel işaretleri ortadan kaldırmaktadır. Böyle bir toplumsal yapı içerisinde birey, her yerde başkalarıyla değil, sadece kendisiyle karşılaşmakta ve diğerleriyle kendisi arasında bir kıyaslama yapamadığından kendilik imgesini inşa edememektedir. Bu nedenle kendisiyle fazlaca meşgul olmak durumunda bırakılan birey, narsistleşmektedir.

Han'a (2017, s.60) göre şeffaf toplum, enformasyon toplumudur. Çünkü enformasyon, kendi başına her türlü olumsuzluktan yoksunlaştırılarak bir şeffaflık bileşenine dönüştürülmektedir. Bu bağlamda, enformasyonu olumlulaştırılmış, işlemleştirilmiş bir dil olarak değerlendirmek mümkündür. Han'ın, şeffaf toplum ve enformasyon arasındaki ilişkiye getirdiği eleştiriye aşağıda yer verilmektedir (2017, s. 61):

\begin{abstract}
"Şeffaflık toplumu sadece hakikatten değil görünüşten de yoksundur. Ne hakikat ne de görünüş şeffaftır. Tümüyle şeffaf olan tek şey boşluktur. Bu boşluğu bertaraf etmek için enformasyon yığını devreye sokulur. (...) Enformasyon ve iletişimin artması kendi başına dünyaya aydınlık getirmez. (...) Enformasyon yığını hakikat oluşturmaz. Ne kadar çok enformasyon serbest kalırsa dünya o kadar karmaşıklaşır. Hiper-enformasyon ve hiper-iletişim karanlıkta bir ışık olamaz."
\end{abstract}

3 Han, burada sosyal ağların bireyin karşısına kendi ilgileriyle benzer olan diğer bireylere ilişkin önerileri sunduğuna değinmektedir. Buna göre, bireyler kendi ilgilerine benzer ilgiye sahip olan bireylerle karşılaştıkça ya da kendi düşüncelerini destekleyen fikirleri daha yüksek sıklıkta gördükçe alternatifin olmadığını ya da yanlış olduğunu düşünmeye başlamaktadırlar. Böylelikle birey, tüm farklı fikirlerle eşit düzeyde alakalar olabileceği bir alanın varlığından da uzaklaşmaktadır. 
Ek olarak yazar, toplumun şeffaflaşmasının Bentham'ın panoptikonunu ${ }^{4}$ yeniden gündeme getirdiğinin de altını çizmektedir. Han'a göre, iletişimin heryerdeliği bireyleri de kendi istekleriyle bu sosyal ağlara katılmaya teşvik etmektedir. Dolayısıyla yazar, Bentham'ın temellerini attığı panoptikonun da dijital dönüşümünün gerçekleştiğini savunmaktadır. Çünkü Han'a göre, bu dijital kontrol toplumu, tıpkı Bentham'ın ifade ettiği panoptikon kavramsallaşması gibi, bireyin özgürlügünü sömürmektedir. Fakat bu yapılanmada Bentham'ın kavramsallaştırmasından farklı olan, kontrol toplumu sakinlerinin çeşitli zorunluluklar nedeniyle değil de, kendi istekleriyle bu gözetlenmeye katılmalarıdır. Bu bağlamda Han, Bentham'ın panoptikon kavramsallaştırmasının kontrol toplumundaki dijital panoptikona doğru nasıl evrilip, farklılaştığını aşağıdaki gibi aktarır (2017, s. 67);

"Şu an panoptikonun sonunu değil, tümüyle yeni, perspektifsiz bir panoptikonun başlangıcını yaşıyoruz. 21.yüzyılın dijital panoptikonu artık tek bir merkezden, despotik bakışın her şeye kadir gücü tarafından gözlemlenmiyor olması ölçüsünde perspektifsizdir. Bentham'ın panoptikonunun temel öğesi durumundaki merkezçevre ayrımı tümüyle yok olmuştur. Dijital panoptikon herhangi bir perspektife dayanan optik olmaksızın iş görür. Verimliliğini de buna borçludur. Perspektiften yoksun bir şekilde ışığa boğma perspektife dayanan gözetlemeden daha etkilidir, çünkü insan her yandan, her açıdan, hatta herkes tarafından aydınlatılabilir."

Ayrıca Bentham'ın panoptikonunun içinde yer alan bireyler, gözcünün sürekli varlığının farkında ilken dijital panoptikonun sakinleri özgür olduklarını düşünmektedirler. Han'a (2017, s.68) göre, günümüz kontrol toplumunun özel bir panoptik yapısı bulunmaktadır. Bentham'ın panoptikonundaki yalııımış mahkumların aksine, günümüz panoptikonunun sakinleri birbirleriyle yoğun bir biçimde iletişim kurmakta ve ağlar oluşturmaktadır. Burada şeffaflığı garantileyen yalıtılmışığın getirdiği yalnızlık değil, hiper-iletişimdir. Dijital panoptikonun kendine has yanı, kuruluşunda ve sürdürülmesinde sakinlerinin soyunma ve kendilerini teşhir etme yoluyla aktif olarak yer almalarıdır. Bireyler bu şeffaf toplum içerisindeki panoptik pazarda kendilerini sergilemektedirler. Bu da günümüzün panoptikonu niteliğindeki interneti beslemektedir. Dolayısıyla, dijital panoptikon tarafından gözetlenen bireyler sürekli olarak gözetlendiklerinin farkında da değillerdir ve bu gözetlenmeye istekli olarak dahil olduklarını söylemek mümkündür. Han bireylerin gözetlenme sürecine katıımlarını aşağıdaki gibi aktarmaktadır (2017, s.71-72):

\footnotetext{
"Tüketiciler ihtiyaçlarını yönlendiren ve tatmin eden panoptik gözetime gönüllü olarak teslim ederler kendilerini. Bu noktada artık sosyal medya ile panoptik makineler arasında fark yoktur. Iletişim ve ticaret, özgürlük ve kontrol aynı şey
}

4 Jeremy Bentham'ın panoptikon kavramsallaştırması, temel olarak bir hapishane formunda bir gözetleme evinin oluşturulması fikrine dayanmaktadır. Bentham'ın ifadesiyle bu gözetleme evinin her bir hücresi $(1971$, s. 6); tek bir ortak merkezden dışarıya doğru açılmaktadır, gözetleyen kişinin görebileceği bir biçimde aydınlatılıştır ve bütün gözetlenenlerin diğerleriyle olan ilişkisi kesilmiştir. Bununla birlikte hücrelerdeki mahkumlar kendilerini gözetleyeni görememektedirler. Böylelikle mahkumlar ne zaman gözetlenip gözetlenmediklerinin farkında olmamakta, sürekli gözetlendiklerini düşünmektedirler. 
haline gelir. (...) Kendilerini özgürlük alanları olarak sunan Google ve sosyal ağlar panoptik biçimlere bürünüyorlar. Bugün gözetleme, genelde sanıldığı şekliyle özgürlüğe saldırı şeklinde gerçekleşmiyor. Insanlar daha ziyade kendilerini gönüllü olarak teslim ediyorlar panoptik bakışa. Kendilerini soyarak ve teşhir ederek dijital panoptikonun oluşuna bilerek katkıda bulunuyorlar."

Diğer yandan, bu gözetleme ve gözetlenme hali, asimetrik bir ilişki içerisinde gerçekleşmemektedir. Sadece iktidar sahipleri değil, her birey bu gözetleme ve gözetlenme imkanını elde etmiş durumdadır. Han'a (2017, s.69) göre bu topyekun gözetleme, şeffaf toplumu insanlık dışı bir kontrol toplumuna dönüştürmektedir. Bu toplumda, herkes herkesi kontrol etmektedir. Diğer yandan Han, Bentham'ın panoptikon girişiminin ahlaki kaygıları olduğundan bahsetmekte, fakat günümüz dijital panoptikonunun ekonomik bir alt yapısının bulunduğuna da dikkat çekmektedir. Çünkü bireyin bu dijital panoptikona katıımı onu, ekonomik bir sömürü nesnesi haline getirmektedir.

Son olarak Han, dijital panoptikonun var olduğu şeffaf bir toplumun bir cemiyet olma özelliğini de yitirdiğine de değinmektedir. Bu toplumda (2017, s.71) sadece ortak bir çıkar ya da ilgileri veya bir markanın çevresine toplanan yalıtımış bireylerin ve egoların tesadüf eseri ortaya çıkan toplaşmalarına ya da kümelenmelerine rastlanmaktadır. Bu topluluklar, eklemelerle ortaya çıkmaları dolayısıyla biz duygusunu oluşturmaktan da oldukça uzaklardır. Dolayısıyla şeffaf toplum yapısı içerisinde artık cemaatlerin yerini kümelerin aldığını söylemek yanlış olmayacaktır.

\section{Sonuç}

Byung-Chul Han tarafından kaleme alınan şeffaflık toplumu isimli çalışma, iletişim teknolojilerinin gelişmesiyle birlikte, toplumsal yapıda meydana gelen değişimleri eleştirel bir bakışla ele almaktadır. Bu bağlamda, şeffaf toplum kavramsallaştırması ve bu kavramsallaştırmaya ilişkin temel özelliklerin günümüz toplumunun değişen yapısı hakkında okuyucuya yeni bir perspektif sunduğu düşünülmektedir. Diğer yandan çalışma, dijital iletişim teknolojileri ve beraberinde sosyal ağlar aracıı̆ğıla kurulan bireyler ve gruplararası iletişim biçimindeki farklılaşmalara değinmesi bakımından da önem taşımaktadır. Dolayısıyla, çalışmanın temel dayanakları bakımından iletişim disiplini açısından da önemini vurgulamak gerekmektedir.

Ek olarak, Han'ın şeffaflaşan toplumsal yapının dayanakları olarak aktardığı olumluluk toplumu, teklifsizlik toplumu, kontrol toplumu, dijital panoptikon gibi kavramsallaştırmaların, alana yeni bakış açıları sunduğu da görülmektedir. Ayrıca Han'ın çalışması, Bentham, Benjamin, Foucault gibi düşünürlerin görüşlerini de şeffaf toplum kavramsallaştırması üzerinden yeniden yorumlamaktadır. 
Günümüz toplumunda dijital iletişim teknolojilerinin ve beraberinde sosyal ağların yeri göz önünde bulundurulduğunda; alana ilişkin eleştirel çalışmalar yeni toplumsal sorunlara işaret etmesi bakımından önem kazanmaktadır. Bu kapsamda, şeffaflaşan toplumsal yapıdaki özgürlük anlayışının bir kontrol toplumu içerisinde yeniden yapılanma biçiminin de çalışma içerisinde ele alınan bu yeni sorunlardan biri olduğunu söylemek mümkündür. Bu nedenle, teknolojik gelişimlerin toplumsal yapıyı farklılaştırmasına ilişkin disiplinler arası bir yaklaşım sunan bu çalışmanın okuyucusuna keyifli okumalar sunacağı düşünülmektedir.

\section{Kaynakça}

Jeremy Bentham (1971). Panopticon or the Inspection House. Vol. 2. London \& Dublin: News Gate.

Han, Byung-Chul (2017). Şeffafılık Toplumu. İstanbul: Metis Yayınları. 